\title{
LA REFORMA ESTATUTARIA EN CASTILLA Y LEÓN ${ }^{1}$
}

\author{
LUIS E. DELGADO DEL RINCÓN \\ Profesor Titular de Derecho Constitucional \\ Universidad de Burgos
}

\author{
SUMARIO \\ I. Introducción. \\ II. Algunas de las señas de identidad de \\ Castilla y León contenidas en el Título \\ Preliminar: la definición de la Comuni- \\ dad, el territorio y la lengua. \\ III. Los derechos y principios. \\ IV. Las competencias de la Comunidad: las \\ aguas y la cuenca del Duero. \\ V. La reforma del Estatuto.
}

\section{INTRODUCCIÓN}

Los arts. 81.1 y 147 de la Constitución son dos preceptos clave para determinar lo que se entiende por Estatuto de Autonomía. El primero de ellos, teniendo en cuenta la forma de elaboración, dispone que el Estatuto debe aprobarse mediante ley orgánica. El segundo define la posición que ha de ocupar en el ordenamiento jurídico así como su contenido. De este modo, en su primer apartado, se reconoce que el Estatuto será "la norma institucional básica de cada Comunidad Autónoma", siendo reconocido y amparado por el Estado como parte integrante de su ordenamiento jurídico. En su apartado segundo se establecen las materias que todo Estatuto de Autonomía ha de contener: «a) La denominación de la Comunidad que mejor corresponda a su identidad histórica; b) La delimitación de su territorio; c) La denomi-

1 Este trabajo se ha realizado en el marco de los Proyectos de investigación BU004B07, sobre Comunidad Autónoma, entidades locales e inmigración, concedido por la Consejería de Educación de la Junta de Castilla y León (2007-2008) y DER2008-00185/JURI, sobre Pluralidad de Ciudadanías y participación democrática, concedido por la Subdirección de Proyectos de Investigación del Ministerio de Ciencia e Innovación (2008-2011)

UNED. Teoria y Realidad Constitucional, núm. 24, 2009, pp. 293-322. 
nación, organización y sede de las instituciones autónomas propias; d) Las competencias asumidas dentro del marco establecido en la Constitución y las bases para el traspaso de los servicios correspondientes a las mismas". En el apartado tercero se incluye una regla sobre su reforma, al disponer que ésta «se ajustará al procedimiento establecido en los mismos y requerirá, en todo caso, la aprobación por las Cortes Generales, mediante ley orgánica". Esta exigencia dota ya a los Estatutos de cierta rigidez.

La aprobación de los Estatutos de Autonomía por ley orgánica (art. 81.1 CE) hace que éstos entren a formar parte del ordenamiento del Estado (art. 147.1 CE). Ahora bien, ello no significa que sean leyes orgánicas, ya que, según previsión constitucional, constituyen también la norma institucional básica de cada Comunidad Autónoma, lo que les convierte en la norma primaria del ordenamiento autonómico ${ }^{2}$.

El Estatuto de Autonomía de Castilla y León fue aprobado el 25 de febrero de 1983, desde entonces y durante los veinticinco años de vigencia, se ha erigido en el marco jurídico de convivencia de los ciudadanos de esta comunidad, organizando sus instituciones y determinando las materias objeto de su competencia. Antes de la amplia y profunda reforma de 2007, el Estatuto de Autonomía de Castilla y León había sido objeto también de dos reformas importantes por LO 11/1994, de 24 de marzo y por LO 4/1999, de 8 de enero.

La reforma de 1994 es una reforma competencial, en virtud de la cual y como consecuencia de los Acuerdos Autonómicos de 28 de febrero de 1992, suscritos por el Gobierno de la nación, el PP y el PSOE, la Comunidad de Castilla y León, al igual que el resto de las Comunidades Autónomas que accedieron a la Autonomía por la vía lenta, procedió a una ampliación ordenada y racional de las competencias autonómicas, dentro de los límites fijados por el art. $149 \mathrm{CE}$.

La reforma de 1999 apenas afecta a las competencias, aunque se produzca una ligera ampliación. Se trata de una reforma que persigue elevar las cotas de

2 Sobre los Estatutos de Autonomía, vid., entre otros, AGUADO RENEDO, C., El Estatuto de Autonomía y su posición en el ordenamiento jurídico, Madrid, 1996, págs. 211-582 y "De nuevo sobre la naturaleza jurídica del Estatuto de Autonomía, con motivo de los procesos de reforma", Asamblea. Revista parlamentaria de la Asamblea de Madrid, n. ${ }^{\circ}$ 17, diciembre de 2007, págs. 283 y ss.; TORNOS MAS, J., "Los Estatutos de las Comunidades Autónomas en el Ordenamiento jurídico español", Revista de Administración Pública, n. ${ }^{\circ}$ 91, 1980, págs. 125-169; MARTíN OVIEDO, J. M., "Estatutos de Autonomía: su contenido y reforma. Artítulo 147", en Comentarios a la Constitución española de 1978 (Dir. O. Alzaga), tomo XI, Madrid, 1996-1999, págs. 123-143; MARTÍNEZ SOSPEDRA, M., "La reforma del Estaturo de Autonomía: procedimiento y contenido", en Instituciones políticas de la Comunidad Valenciana (coord. V. Garrido), Valencia, 1999, págs. 237-244; ARAGÓN REYES, M., "La reforma de los Estatutos de Autonomía", en Estudios de Derecho Constitucional, Madrid, 1998, págs. 383 y ss.; CASTELLÁ ANDREU, J.M., La función constitucional del Estatuto de Autonomía de Cataluña, Barcelona, 2004, págs. 10 y ss.; la obra colectiva sobre La reforma de los Estatutos de Autonomía, Actas del VI Congreso Nacional de la Asociación de Constitucionalistas de España, Valencia, 2006, págs. 17 y ss. y MUÑOZ MACHADO. M., "Los Estatutos de Autonomía", Derecho Público de las Comunidades Autónomas, tomo I, Madrid, 2007, págs. 309-336. 
autogobierno, completando el marco institucional de la Comunidad al incorporar al Estatuto de Autonomía el Procurador del Común o al prever la creación de dos nuevos órganos: el Consejo de Cuentas y el Consejo Consultivo.

La reforma de 2007 ha de situarse en un contexto de iniciativas generalizadas de reformas estatutarias que han tenido lugar en la legislatura anterior, debido, sobre todo, al impulso reformador acometido por los Gobiernos autonómicos vasco y catalán que habían alcanzado ya el máximo techo competencial $^{3}$. Sin embargo, y a diferencia de las anteriores, no se inspira en un acuerdo adoptado entre el Gobierno de la nación y los dos grandes partidos de ámbito nacional que pueda servir de modelo unitario de refor$\mathrm{ma}^{4}$, sino que conlleva también un aumento de las competencias de la Comunidad. No obstante, por otras circunstancias singulares, podría calificarse dicha reforma como la reforma de los ciudadanos o la reforma de las señas de identidad de la Comunidad'5 .

Estamos, además, ante una reforma amplia y profunda porque son varias y de gran calado las novedades que introduce. Entre otras, pueden destacarse las siguientes: a) el reconocimiento expreso en el Título Preliminar de las señas de identidad de la Comunidad Autónoma como la definición de comunidad histórica y cultural, la delimitación del territorio castellano leonés o el valor de la lengua castellana; b) el establecimiento en el Título I — de nueva factura- de un catálogo de derechos de los castellanos y leoneses, en el que se definen también los principales objetivos de la acción política de la Comunidad; c) la regulación más completa en el Título II de las instituciones básicas de la forma de gobierno parlamentaria, en particular, la posición del Presidente de la Junta de Castilla y León con sus atribuciones o las relaciones entre las Cortes y la Junta de Castilla y León y su Presidente; d) la determinación en el nuevo Título III de la forma de organización territorial de la Co-

3 Para el profesor PÉREZ ROYO, J., "La reforma del Estado autonómico", en El Estatuto de Autonomía de Andalucía de 2007 (Coord. de M. Agudo Zamora), Sevilla, 2008, pág. 53, las reformas estatuarias que se están acometiendo son de una intensidad tan extraordinaria que "los nuevos Estatutos no son propiamente reformas de los Estatutos originarios, sino que son Estatutos nuevos, que vienen a sustituir más que a reformar a aquéllos. Basta comparar a unos y otros. En la extensión, en las nuevas materias que se regulan, en el detalle con que se regulan las materias que estaban reguladas en los Estatutos originarios (...), con la relativa excepción de la fórmula parlamentaria de gobierno, nos encontramos ante una nueva norma, no ante una reforma de la antigua".

4 Cfr. sobre estas reformas del Estatuto de Autonomía de Castilla y León, BILBAO UBILLOS, J. M., "Iniciativa autonómica y sucesivas reformas del Estatuto de Autonomía de Castilla y León", Derecho Público de Castilla y León (Dir. I. Sáez Hidalgo), Valladolid, 2008, págs. 99-124.

5 Así es calificada por REY MARTÍNEZ, F., en un manuscrito amablemente cedido por el autor. De él tomamos también algunas de las características de la reforma que fueron resaltadas por el Presidente de la Comunidad Autónoma, D. Juan Vicente Herrera Campo, en el discurso que iniciaba el proceso de reforma del Estatuto: el debate parlamentario sobre el estado de la Región, de 22 de junio de 2.005. En él se hablaba de "una reforma personalizada para Castilla y León", de "una reforma que trataría de profundizar en nuestro autogobierno", de "una reforma de calidad y de altura técnica" y de "una reforma que debería ser fruto del consenso parlamentario". 
munidad, potenciando el desarrollo de la autonomía de los entes locales, previendo mecanismos de relación entre éstos y las instituciones de la Comunidad y posibilitando la creación de comarcas como se hace expresamente con la del Bierzo; e) la regulación más precisa en el Título IV de las relaciones de cooperación de nuestra Comunidad con el Estado y las demás Comunidades Autónomas, presididas por los principios de solidaridad y lealtad institucional, situando a la Comunidad de Castilla y León en Europa y en el mundo, otorgándole expresamente un derecho de participación en los asuntos europeos que afecten a sus competencias o intereses; f) la ampliación y consolidación en el Título V de las competencias de la Comunidad, perfilando con precisión algunas de las materias más sensibles, como la educación, la sanidad, la seguridad o la gestión del agua; g) la previsión en el Título VI de los instrumentos necesarios para la obtención de los recursos suficientes para garantizar el disfrute de los servicios públicos por los castellanos y leoneses; h) la concreción en el Título VII de un procedimiento de reforma del Estatuto que es el resultado del acuerdo de dos voluntades representadas por las Cortes de Castilla y León y por las Cortes Generales.

Veamos a continuación algunas de las novedades más significativas introducidas por la reforma de 2007, siguiendo la sistemática utilizada en nuestra Norma institucional básica.

\section{ALGUNAS DE LAS SEÑAS DE IDENTIDAD DE CASTILLA Y LEÓN CONTENIDAS EN EL TÍTULO PRELIMINAR: LA DEFINICIÓN DE LA COMUNIDAD, EL TERRITORIO Y LA LENGUA}

a) Una de las novedades más importantes de la reforma del Estatuto ha sido la definición que en el art. 1.1 del Título Preliminar se hace de nuestra Comunidad Autónoma ${ }^{6}$. El anterior Estatuto de Autonomía no contenía una definición de Castilla y León. En su art. 1.1, simplemente se manifestaba la intención de constituirse en Comunidad Autónoma como expresión de su identidad histórica", mencionando "la vinculación histórica y cultural de las provincias que la integran". No obstante, se concebía al Estatuto como Norma institucional básica de la Comunidad y se otorgaba a ésta personalidad jurídica propia.

Con la reforma el Estatuto define a Castilla y León como «una comunidad histórica y cultural que tiene su origen en los antiguos Reinos de León y Castilla", reconociendo además la contribución que ha tenido "de modo decisivo a la formación de España como Nación". Como puede constatarse, no se utilizan para su definición los términos de nación, nacionalidad o región. Asimismo, desde una perspectiva histórica y reforzando lo manifestado en el Preám-

6 Ha de tenerse en cuenta que la definición de Comunidad Autónoma que se hace en otros Estatutos de Autonomía, como el catalán, ha sido objeto de recurso de inconstitucionalidad ante el Tribunal Constitucional. 
bulo del Estatuto, se alude a la intervención que los reinos de León y Castilla han tenido en el nacimiento de nuestra Comunidad y a la participación que ésta tuvo en la creación del Estado español. Según la opinión de Fajardo Casajús, el Estatuto configura a Castilla y León como una "comunidad surgida de la unión de dos reinos históricos, el de Castilla y el de León, con vínculos históricos y culturales comunes", como "una lengua, un patrimonio y un devenir histórico" (...). Esta denominación pretende reafirmar la identidad común del pueblo de Castilla y León, dentro de la unidad indisoluble del España" ${ }^{7}$.

El art. 1, apartado segundo, define también a Castilla y León como "una Región de Europa" que "asume los valores de la Unión Europea y vela por el cumplimiento de sus objetivos". En esta nueva norma se deja ya constancia de una realidad, el papel que tienen las regiones en el seno de la Unión Europea, a través de los Estados de los que forman parte, o también a través de una institución de la Unión, como es el Comité de las Regiones. Estos aspectos se desarrollarán posteriormente en el texto del Estatuto en un capítulo, también novedoso, como es el capítulo segundo del Título IV, relativo a las "relaciones con la Unión Europea y participación en la política europea del Estado" ${ }^{8}$.

b) El territorio de la Comunidad de Castilla y León se define expresamente en el art. 2 del Estatuto, al establecer que "comprende el de los municipios integrados en las actuales provincias de Ávila, Burgos, León, Palencia, Salamanca, Segovia, Soria, Valladolid y Zamora". Este precepto introduce como novedad, respecto del anterior art. 2, la introducción del adjetivo "actuales" antes del sustantivo "provincias". Esta redacción pone fin a una polémica cuestión que se suscitaba con la redacción del Texto anterior: si el territorio de la Comunidad estaba constituido por las nueve provincias con los límites que éstas tenían al aprobarse el Estatuto o, por el contrario, estaba integrado por el territorio de los municipios que en cada momento formasen parte de las citadas provincias, de tal manera que un municipio podía pasar a formar parte de otra Comunidad sin reformar el Estatuto?.

A esta cuestión ya se refirió el Tribunal Constitucional, en la STC 99/1986, de 11 de julio, cuando reconoció, en relación con la delimitación

7 Vid. FAJARDO CASAJÚS, C., "La Comunidad de Castilla y León", Derecho Público de Castilla y León, Valladolid, 2008, págs. 128-129.

8 En este capítulo, se reconoce, por primera vez, a la Comunidad el derecho a ser informada y oída por el Estado, así como a participar en los asuntos europeos que afecten a sus competencias o intereses (art. 61). De igual modo, se otorga a la Comunidad la facultad de participar en las instituciones y órganos de la Unión europea, dentro de la representación del Estado español (art. 63.1), atribuyendo, incluso, a la Junta de Castilla y León la posibilidad de proponer al Estado la designación de representantes en el Comité de las Regiones (art. 63.2). También se la faculta para establecer una Delegación Permanente ante la Unión con el objeto de mantener relaciones de colaboración con las instituciones europeas (art. 64); o para actuar ante el Tribunal de Justicia, ya sea directamente o instando al Gobierno de la nación para que sea éste el que ejerza las acciones oportunas en defensa de los intereses de de Castilla y León (art. 65.1 y 2).

9 Ibidem, págs. 133-134. Fajardo Casajús, cuando aborda el tema del ámbito territorial, menciona también otros problemas que se han planteado en nuestra Comunidad como los casos de las provincias de Segovia y León o el enclave del Condado de Treviño (págs. 131-133). 
territorial del Estatuto de Autonomía del País Vasco, que "se introduce así en el Estatuto una específica garantía territorial mediante la cual los límites geográficos con los que se constituyó al nacer la Comunidad Autónoma quedan consagrados en su norma institucional básica (...) Esta segunda forma de delimitación del territorio impide toda alteración del mismo que no se realice mediante el procedimiento establecido para la revisión del Estatuto, a no ser que en éste se contengan reglas específicas para llevar a cabo dichas alteraciones" ${ }^{10}$.

c) La lengua castellana es concebida en el art. 4 del Estatuto como valor esencial para la identidad de la Comunidad de Castilla y León. El art. 5.1 concreta, además, que "forma parte del acervo histórico y cultural más valioso de la Comunidad, extendido a todo el territorio nacional y a muchos otros Estados». A continuación, se introduce una norma de carácter competencial, al imponer a la Junta de Castilla y León la obligación de fomentar su uso correcto en los ámbitos educativo, administrativo y cultural. De igual manera, se obliga a la Junta, esta vez en colaboración con las Universidades de la Comunidad, a promover su aprendizaje en el ámbito internacional, "para lo cual podrá adoptar las medidas que considere oportunas".

A estos efectos, con anterioridad a la aprobación de la reforma estatutaria, la Junta de Castilla y León, mediante el Decreto 92/2007, de 20 de septiembre, ha creado la figura del Comisionado para la Lengua Española, como órgano unipersonal dependiente del Presidente de la Junta, que tiene por objeto garantizar la protección y apoyo a la Lengua castellana, así como también garantizar la eficacia de las actuaciones del Plan del Español para Extranjeros de Castilla y León. Esta disposición ha conllevado que se dicte, a su vez, otro Decreto, el 100/2007, de 11 de octubre, por el que se modifica la composición de la Comisión de Coordinación del Plan del Español para Extranjeros de Castilla y León. De esta manera, la lengua castellana pasa a considerarse como un importante activo económico, como una industria cultural de gran trascendencia para nuestra Comunidad.

Otra de las novedades del art. 5 del Estatuto es la mención expresa al leonés, concibiéndole, a diferencia del castellano que es un valor esencial de la Comunidad, como un elemento valioso "del patrimonio lingüístico de la Comunidad", por lo que habrá de ser "objeto de protección específica por parte de las instituciones". Con esta alusión expresa del leonés se corrige el olvido del anterior Estatuto, que simplemente hablaba de "modalidades lingüísticas", sin especificar cuáles eran. Modalidades lingüísticas cuyo reconocimiento estatutario es coherente con lo dispuesto en el art. 3.3 CE, cuando dice que "la riqueza de las distintas modalidades lingüísticas de España es un patrimonio cultural que será objeto de especial respeto y protección".

10 Cfr. la STC 99/1986, de 11 de julio (FFJJ $4 .^{\circ}$ y $5 .^{\circ}$ ). 


\section{LOS DERECHOS Y PRINCIPIOS}

Una de las innovaciones más trascendentales es la introducción, en el Título I, de una carta, catálogo o tabla de derechos a favor de los ciudadanos de Castilla y León, siguiendo la tendencia adoptada por otros Estatutos de Autonomía como el catalán, el valenciano, el balear o el andaluz, aunque con alguna diferencia en relación con su contenido o extensión ${ }^{11}$.

El Título I, bajo la rúbrica "Derechos y principios rectores", no sólo enumera de forma amplia y extensa los derechos de los ciudadanos castellanos y leoneses o los principios rectores que han de regir la actuación de los poderes públicos de la Comunidad, sino que, en diferentes capítulos, establece también algunos deberes e introduce determinadas disposiciones generales sobre la titularidad de los derechos, su eficacia y garantías.

La incorporación en las últimas reformas estatutarias de un catálogo de derechos ha dado lugar a un interesante debate en la doctrina constitucionalista ${ }^{12}$, habiendo llegado incluso la cuestión hasta el Tribunal Constitucional, como se deduce de la STC 247/2007, de 12 de diciembre.

11 Ya en el Preámbulo del Estatuto se apunta porqué se introduce este catálogo de derechos. En él se dice que "se reconocen derechos sociales de los ciudadanos de Castilla y León, que quedan así mejor protegidos (...). El Título I, de nueva factura, incluye un catálogo de derechos de los castellanos y leoneses y define los principales objetivos de la acción política de la Comunidad, dando cuerpo jurídico a la idea de un Estatuto de Autonomía que se define no sólo como norma institucional básica, sino también como garante de los derechos y del bienestar de los ciudadanos".

12 Este debate doctrinal se ha plasmado, entre otros, en los siguientes trabajos: GARCÍA TORRES J., "Los derechos estatutarios en la propuesta catalana de reforma", en el Estado Autonómico, Madrid, 2006, págs. 57-73; FERRERES COMELLAS, V., BIGLINO CAMPOS, P. y CARRILLO, M., Derechos, deberes y principios en el nuevo Estatuto de Autonomía de Cataluña, Madrid, 2006, págs. 9-88; DÍEZ-PICAZO, L.M., "¿Pueden los Estatutos de autonomía declarar derechos, deberes y principios?", Revista Española de Derecho Constitucional, n. ${ }^{\circ}$ 78, 2006, págs. 63-75; CAAMAÑO DOMÍNGUEZ, F., "Sí, pueden: declaraciones de derechos y Estatutos de Autonomía", Revista Española de Derecho Constitucional, n. ${ }^{\circ}$ 79, 2007, págs. 33-46; CARRILLO, M., "Los derechos, un contenido constitucional de los Estatutos de Autonomía", Revista Española de Derecho Constitucional, n. ${ }^{\circ}$ 80, 2007, págs. 49-73; DÍEZ-PICAZO, L.M., "De nuevo sobre las declaraciones estatutarias de derechos: respuesta a Francisco Caamaño", Revista Española de Derecho Constitucional, n. ${ }^{\circ}$ 81, 2007, págs. 63-70; VILLAVERDE MENÉNDEZ, I., "La intangibilidad competencial de los derechos fundamentales. Forma de Estado y derechos fundamentales", Teoría y Realidad Constitucional, n. ${ }^{\circ}$ 20, 2007, págs. 321-357; CANOSA USERA, R., "La declaración de derechos en los nuevos Estatutos de Autonomía", Teoría y Realidad Constitucional, n. ${ }^{\circ}$ 20, 2007, págs. 61-115; la encuesta sobre Derechos fundamentales realizada a diversos autores en la revista Teoría y Realidad Constitucional, n. ${ }^{\circ} 20,2007$, págs. 11-57; PORRAS NADALES, A., "Derechos sociales y políticas públicas", en El Estatuto de Autonomía de Andalucía de 2007 (coord. de M. Agudo Zamora), Sevilla, 2008, págs. 107-123; APARICIO, M.M. (ed.), Derechos y principios rectores en los Estatutos de Autonomía, Barcelona, 2008, págs. 13 y ss., obra colectiva en la que se contienen trabajos de diversos profesores sobre la regulación del tema de los derechos y principios rectores en los Estatutos de Autonomía de Cataluña, Valencia, Illes Balears, Andalucía, Aragón, Castilla León y Castilla-La Mancha y MATIA PORTILLA, J., "¿Un Estatuto paraconstitucional? Consenso, nación histórica y Declaración de derechos", Revista Jurídica de Castilla y León, n.. 17, 2009, págs. 23-66. 
En la doctrina, los profesores que son contrarios a la proclamación de derechos en los Estatutos de Autonomía han esgrimido, entre otras, las siguientes razones. Desde una perspectiva de fondo, entienden que las declaraciones de derechos son un contenido típico de las Constituciones, llegando a existir una reserva absoluta de Constitución en esta materia, de tal modo que las Cortes Generales, al aprobar los Estatutos de Autonomía, no pueden otorgar unos derechos a unos españoles y otros derechos a otros ${ }^{13}$. Desde una perspectiva formal, consideran que el reconocimiento de derechos no es una materia que aparezca recogida expresamente en el art. 147.2 CE como contenido típico de los Estatutos de Autonomía, por lo que su introducción podría ser contraria a la Constitución ${ }^{14}$.

Por el contrario, el sector doctrinal que se muestra favorable a la inclusión de las declaraciones de derechos en los Estatutos de Autonomía esgrime, entre otros, los siguientes argumentos. Que no se está en presencia de derechos fundamentales, sino que se trata de derechos estatutarios que vinculan solamente a los poderes autonómicos ${ }^{15}$. Que el contenido del Estatuto de Autonomía no "puede verse constreñido" a las materias previstas en el artículo 147.2 CE, sino que pueden existir "materias propias del autogobierno" que pueden ser también "un contenido posible" del Estatuto, como las declaraciones de derechos, siempre que vinculen a los poderes públicos autonómicos y que su inclusión no conlleve una alteración del reparto de competencias existente entre el Estado y las Comunidades Autónomas ${ }^{16}$.

En esta línea, la profesora Biglino Campos, cuando aborda la reforma del Estatuto de Autonomía de Castilla y León, considera que su Título I no contiene una declaración de derechos que pueda asimilarse a la de las Constituciones de nuestro entorno, sino que incluye, sobre todo, principios que solamente, "en contadas ocasiones, constituyen auténticos derechos subjetivos". Por otro lado, siguiendo la opinión de esta autora, si se tiene en cuenta la forma en que actúan los derechos en una forma de Estado compuesto que, en virtud de su dimensión objetiva, constituyen, de un lado, límites a la actuación de los poderes públicos y, de otro, mandatos dirigidos a éstos para que orienten sus políticas hacia fines tendentes a la consecución del bienestar de los ciudadanos, los Estatutos de Autonomía pueden incluir en su articulado derechos y principios, ya que, como se ha dicho, estas Normas insti-

13 Cfr. DÍEZ-PICAZO, L.M., "¿Pueden los Estatutos de autonomía declarar derechos...”, ob. cit., p 71 y GARCÍA TORRES J., "Los derechos estatutarios en la propuesta catalana de reforma...", ob. cit., págs. 66-69.

14 Vid. DÍEZ-PICAZO, L.M., "¿Pueden los Estatutos de autonomía declarar derechos...", ob. cit., pág. 70 .

15 Cfr. CANOSA USERA, R. "Sí, pueden: declaraciones de derechos...", ob. cit., pág. 33.

16 Vid. CARRILlo, M., "Los derechos, un contenido constitucional....", ob. cit., págs. 53-56. En términos similares se pronuncian VILLAVERDE MENÉNDEZ, I., "La intangibilidad competencial de los derechos...", ob. cit., pág. 356 y CANOSA USERA, R., "La declaración de derechos....", ob. cit., pág. 70. Para este último autor, los derechos estatutarios, que es una categoría singular y distinta de la de los derechos fundamentales, sólo pueden ser aceptados si se conciben como un medio para impulsar, orientar y limitar el ejercicio de competencias propias. 
tucionales básicas de las Comunidades Autónomas tienen precisamente por objeto la regulación del funcionamiento de los órganos de autogobierno y la delimitación de sus competencias ${ }^{17}$. Ahora bien, ha de advertirse también que la proclamación de los derechos y principios por los Estatutos de Autonomía ha de ser congruente con las competencias asumidas por la Comunidad Autónoma y respetuosa con las reservadas por la Constitución al Estado, como así se constata en el catálogo de derechos que se introduce con la reforma de 2007 en el Estatuto de Autonomía de Castilla y León ${ }^{18}$.

El Tribunal Constitucional, en la STC 247/2007, de 12 de diciembre, conoce de un recurso de inconstitucionalidad interpuesto por el Gobierno de la Comunidad Autónoma de Aragón contra un precepto, el art. 17.1 del Estatuto de Autonomía de la Comunidad de Valencia (reformado por la LO 1/2006, de 10 de abril), en el que se reconoce a los valencianos el derecho de redistribución de los sobrantes de aguas de cuencas excedentarias. Para la parte recurrente, la norma estatutaria vulnera los arts. 138.2, 139.1, 147 y 149.1.1 $\mathrm{CE}$, al entender que si «el régimen jurídico de los derechos y libertades de los españoles en el conjunto del territorio nacional debe ser común (...), el mencionado derecho, al no tener relación con los derechos que la Constitución consagra, supone una quiebra de los principios de unidad y de igualdad ${ }^{19}$.

Cuando el Tribunal aborda la cuestión sobre si el art. 17.1 del Estatuto valenciano vulnera o no el art. 139.1 CE, establece, entre otras, las siguientes consideraciones $^{20}$ :

17 Cfr. BIGlinO Campos, P., "Derechos y principios", Derecho Público de Castilla y León, Valladolid, 2008, pág. 147.

18 Ibidem, pág. 148. Esta advertencia había sido expresada también por el Consejo Consultivo de Castilla y León, en el dictamen 713/2006, de 14 de septiembre, en el que se analizaba la consulta planteada por el Presidente de la Junta de Castilla y León sobre la propuesta de reforma de la Ley Orgánica 4/1983, de 25 de febrero, del Estatuto de Autonomía de Castilla y León. GARCÍA ROCA, J., "Tipos de normas de deslinde y criterios para la distribución de competencias territoriales", en Derecho Público de Castilla y León, Valladolid, 2008, pág. 715, mantiene una posición similar, al reconocer que nada impide en la Constitución que el Estatuto de una Comunidad Autónoma regule principios rectores y derechos sociales allí donde tengan un punto de conexión con las competencias que se asuman; de haber una reserva a la Constitución sobre derechos (...), debería ser formal y expresa».

19 Cfr. la STC $247 / 2007$, de 12 de diciembre (FJ $1 .^{\circ}$ ). Un comentario amplio y crítico a esta sentencia puede verse en el trabajo de MATIA PORTILLA, J., "¿Un Estatuto paraconstitucional...", ob. cit., págs. 31-66 y en el libro de FERNÁNDEZ FARRERES, G., ¿Hacia una nueva doctrina constitucional del Estado Autonómico?: Comentario a la STC 247/2007, de 12 de diciembre, sobre el Estatuto de Autonomía de la Comunidad Valenciana, Pamplona, 2008, págs. 11 y ss. Para este último autor, en la STC $247 / 2007$, se puede apreciar una tendencia a proclamar una nueva doctrina constitucional sobre el Estado Autonómico, basada en la tesis de la desconstitucionalización del sistema competencial y en una singular reinterpretación del principio dispositivo (págs. 139140).

$20 \mathrm{El}$ art. 139.1 CE dispone que "todos los españoles tienen los mismos derechos y obligaciones en cualquier parte del territorio del Estado". El Tribunal Constitucional, teniendo en cuenta la relación existente entre los principios de unidad, autonomía, solidaridad e igualdad, se plantea la cuestión sobre si el principio de igualdad, que se proyecta en la esfera de la ciudadanía, constituye un límite infranqueable para que los Estatutos de Autonomía contengan declaraciones de derechos por conllevar la vulneración de los arts. 139.1 y 149.1.1 CE. Para la parte recurrente, 
1. ${ }^{\text {a) }}$ «El art. 139.1 CE no contempla una uniformidad absoluta del régimen de los derechos constitucionales en todo el territorio nacional, sino un principio de igualdad sustancial susceptible de modulaciones diferenciadas en mayor o menor grado en las Comunidades Autónomas, según el tipo de derecho de que se trate y el reparto competencial en la materia implicada ${ }^{21}$. 2. ${ }^{a}$ ) «Los Estatutos de Autonomía, que en el ámbito institucional del contenido estatutario pueden establecer derechos subjetivos por sí mismos, en el ámbito de atribución competencial requieren de la colaboración del legislador autonómico, de tal manera que las prescripciones estatutarias relativas a este último ámbito, cualquiera que sea el modo literal en que se enuncien, han de entenderse (...) como mandatos, orientaciones u objetivos, dirigidos a los poderes públicos autonómicos para el ejercicio de competencias que el Estatuto atribuya" ${ }^{22} .3 .^{\text {a }}$ ) El derecho al agua del art. 17.1 del Estatuto valenciano "no enuncia un derecho ya regulado en la Constitución", no es uno de los "derechos fundamentales y libertades públicas" que la Constitución reconoce y garantiza. En consecuencia, al tratarse de un derecho "enunciado en un Estatuto, no goza de la triple condición que a los derechos constitucionales reconoce el art. 53.1 CE: regulación reservada a la Ley, respeto a su contenido esencial y vinculación a todos los poderes públicos" ${ }^{23}$.

Por estas consideraciones, el Tribunal concluye que el precepto estatutario cuestionado no infringe el art. 139.1 CE, ya que la norma recurrida se relaciona con diversas atribuciones competenciales recogidas en el propio Estatuto valenciano, existiendo, "efectivamente, la conexión que hemos considerado necesaria entre las competencias autonómicas y la regulación controvertida" ${ }^{24}$. Tampoco vulnera el art. 149.1.1 CE, "pues no estamos ante un derecho constitucional", ni el art. 138.2 CE, ya que "del enunciado del art.

habría infracción del art. 139 CE porque la existencia de tablas de derechos estatutarios podría introducir diferencias entre Comunidades Autónomas, dando lugar a que todos los españoles no tengan los mismos derechos y obligaciones en cualquier parte del territorio del Estado. Asimismo, se infringiría el art. 149.1.1 CE, porque la existencia de derechos estatutarios diferenciados se opondría a la competencia del Estado para garantizar "la igualdad de todos los españoles en el ejercicio de los derechos y en el cumplimiento de los deberes constitucionales". Ibidem (FJ $13 .^{\circ}$, en relación con el FJ $4 .^{\circ}$ ).

21 Ibidem (FJ $\left.13 .^{\circ}\right)$.

22 Ibidem (FJ $15 .^{\circ}$ ). En este Fundamento Jurídico, el Tribunal Constitucional recuerda doctrina jurisprudencial anterior para reconocer, en relación con los derechos constitucionales, que "Como consecuencia de su consagración en la Constitución, es claro que los mismos no pueden ser objeto de regulación por los Estatutos de Autonomía. Sin embargo, si el legislador estatutario, simplemente, reprodujera los derechos constitucionales (aunque como ha señalado este Tribunal en reiteradas ocasiones, no es técnicamente correcto transcribir en las leyes los preceptos constitucionales: STC 76/1983, de 5 de agosto, FJ 23; en igual sentido, STC 118/1996, de 27 de junio, FJ 12, entre otras), lo relevante desde la perspectiva de su constitucionalidad será el alcance de dicha reproducción. En tal sentido, si el legislador estatutario va más allá de la mera reproducción e incide en los derechos fundamentales, tales previsiones ( ) sólo serán legítimas si, además, guardan relación con alguna de las competencias asumidas por la Comunidad Autónoma, incurriendo en inconstitucionalidad en caso contrario".

23 Ibidem (FJ 18. ${ }^{\circ}$ ).

24 Ibidem (FJ $20 .^{\circ}$ ). 
17.1 no se desprende que haya de producirse ningún privilegio económico o social para la Comunidad Valenciana ${ }^{25}$.

En definitiva, el Tribunal Constitucional, en esta sentencia, viene a concebir los derechos estatutarios como principios rectores de la política social y económica siempre que estén relacionados con alguna de las competencias asumidas por la Comunidad Autónoma en el Estatuto. Ahora bien, como ya se ha insinuado y se verá más adelante, existen Estatutos de Autonomía, entre los que se encuentra el de Castilla y León, que en sus tablas de derechos no sólo introducen mandatos u orientaciones dirigidos a los poderes públicos autonómicos para el ejercicio de competencias estatutarias, sino que introducen también, en algún caso concreto, verdaderos derechos subjetivos. En este sentido, puede adelantarse que el Estatuto castellano leonés, dentro de su Título I, distingue un capítulo que reconoce derechos de los castellanos y leoneses (el segundo) y otro que proclama los principios rectores de las políticas públicas de Castilla y León (el cuarto). Ahora bien, conviene resaltar que la voluntad del poder estatuyente ha sido la de establecer un régimen jurídico diferente para unos y otros. Así, los derechos del capítulo segundo vinculan a todos los poderes públicos de la Comunidad y, en su caso, también a los particulares, siendo además exigibles en sede judicial, aunque sea bajo las condiciones legalmente establecidas y reservándose su regulación a una ley aprobada por las Cortes de Castilla y León (art. 17.1 y 2 del Estatuto). Por el contrario, los principios rectores del capítulo cuarto informan la legislación, la práctica judicial y la actuación de los poderes públicos, siendo exigibles únicamente ante la jurisdicción, de acuerdo con lo que dispongan las normas que los desarrollen (art. 17.3 del Estatuto).

El Estatuto de Autonomía de Castilla y León, en su Título I, adopta una estructura similar a la del Título I de la Constitución española, al contener en diferentes capítulos normas relativas a la titularidad de los derechos, a los derechos de los castellanos y leoneses, a los deberes, a los principios rectores de las políticas públicas de Castilla y León y a las garantías de los derechos y principios estatutarios.

a) La titularidad de los derechos se otorga a los ciudadanos de Castilla y León, condición que, conforme a lo dispuesto en el art. 7.1, la poseen aquellos españoles que, de acuerdo con las leyes del Estado, tengan la vecindad administrativa en cualquiera de los municipios integrados en el territorio de la Comunidad. La condición de castellano y leonés se superpone a la de español, de tal manera que los castellanos y leones, además de ser titulares de los derechos que la Constitución atribuye a todos los españoles, por el hecho de tener la residencia en Castilla y León, podrán disfrutar también de aquellos derechos que les reconoce el Estatuto.

Ahora bien, de forma excepcional y en determinadas ocasiones, el Estatuto otorga facultades inherentes al ejercicio de ciertos derechos a quienes no tienen la vecindad administrativa en Castilla y León. Este es el caso previsto

25 Idem. 
en el apartado segundo del art. 8, para los españoles residentes en el extranjero y sus descendientes, quienes podrán gozar de los derechos de participación en los asuntos públicos definidos en el artículo 11 del Estatuto, siempre que hayan tenido la última vecindad administrativa en Castilla y León. A estos efectos, el art. 9.1 matiza, para los ciudadanos castellanos y leoneses que se hallen en el exterior, que "los ciudadanos oriundos o procedentes de Castilla y León que residan en otras Comunidades Autónomas de España o fuera del territorio nacional, así como sus asociaciones y centros sociales, tendrán el reconocimiento de su origen o procedencia y el derecho a colaborar y compartir la vida social y cultural de Castilla y León", regulándose por medio de una ley de las Cortes de Castilla y León el alcance y contenido de dicho reconocimiento.

Es más, como novedad importante, el Estatuto, en su art. 10.1, extiende los derechos que en él se reconocen para los ciudadanos de Castilla y León, a los extranjeros que posean la vecindad administrativa en la Comunidad, de acuerdo con lo que establezca el legislador en las leyes posteriores que desarrollen dichos derechos y dentro del marco previsto en la Constitución y en la legislación estatal aplicable en materia de extranjería e inmigración ${ }^{26}$.

b) Desde un punto de vista sistemático, el capítulo segundo del Estatuto establece, en diferentes preceptos, tres tipos de derechos y una mención expresa al principio de igualdad, aunque, en este caso, con un contenido más amplio que el previsto en el art. $14 \mathrm{CE}^{27}$.

Bajo el epígrafe "derechos de participación en los asuntos públicos", se recogen derechos políticos, esto es, derechos que corresponden a los ciudadanos como miembros activos de una comunidad política. En este sentido, el art. 11 reconoce expresamente a los castellanos y leoneses el derecho de

26 Acerca del estatuto jurídico del extranjero y la legislación estatal y autonómica que lo regula, vid. el trabajo de VIDAL FUEYO, C., "Integración económica, social y cultural de inmigrantes", Derecho Público de Castilla y León, Valladolid, 2008, págs. 1206-1220, y la bibliografía que allí se cita. Esta profesora clasifica los derechos que pueden ejercer los extranjeros atendiendo a la situación legal o administrativa en que se encuentren y al ámbito competencial autonómico.

27 Ha de advertirse que el capítulo segundo del Título I del Estatuto reconoce algunos derechos que ya se habían regulado con anterioridad en leyes autonómicas como es el caso de la Ley 18/1988, de 28 diciembre, de Acción Social y Servicios Sociales; la Ley 11/1998, de 5 de diciembre, para la Defensa de los Consumidores y Usuarios de Castilla y León; la Ley 8/2003, de 8 de abril, sobre Derechos y Deberes de las Personas en relación con la Salud o la Ley 1/2007, de 7 de marzo, de medidas de apoyo a las familias de la Comunidad de Castilla y León. Ahora bien, el hecho de que se haya pasado de regular dichos derechos en una norma de rango legal a regularse en una norma estatutaria, conlleva que serán protegidos por la fuerza pasiva del Estatuto de Autonomía, ya que para modificar el precepto estatutario en el que se reconoce un derecho ha de acudirse necesariamente al procedimiento agravado de reforma del Estatuto. Procedimiento que exige, entre otros requisitos, una mayoría cualificada del Parlamento autonómico que, por el contrario, no se necesita para modificar una ley autonómica.

Un breve análisis de los derechos de los castellanos y leoneses, siguiendo la sistemática del Estatuto, puede verse en SEIJAS VILLADANGOS, E., "Derechos de los castellanos y leoneses (Análisis de la regulación de los Derechos en el Estatuto de Autonomía de Castilla y León)", en Derechos y principios rectores en los Estatutos de Autonomía (ed. de M.A. Aparicio), Barcelona, 2008, págs. 297-313. 
sufragio activo y pasivo en las elecciones legislativas autonómicas, con la novedad de poder introducir cuotas electorales de género para acceder a los mandatos representativos autonómicos ${ }^{28}$. Junto a este derecho político, se mencionan en el citado precepto instituciones de democracia participativa ya previstas en el Estatuto anterior, como la iniciativa legislativa popular, o en la Constitución española, como el derecho de petición. Por el contrario, dentro de los derechos políticos del art. 11, sí constituye una novedad la introducción de la iniciativa de referéndum. Así, en su apartado quinto, se otorga a los ciudadanos de Castilla y León el "derecho a promover la convocatoria de consultas populares", siempre que se refieran a "decisiones políticas que sean competencia de la Comunidad" y "en las condiciones y con los requisitos que señalen las leyes, respetando lo dispuesto en el artículo 149.1.32. ${ }^{a} \mathrm{CE}^{29}$.

28 Así, el apartado tercero de este precepto dispone que «la ley promoverá la igualdad efectiva de las mujeres y de los hombres en el acceso a los mandatos representativos autonómicos". A este respecto, ha de tenerse en cuenta la Ley Orgánica 3/2007, de 22 de marzo, para la igualdad efectiva de mujeres y hombres, que introduce, en su Disposición Adicional Primera, la noción de "presencia o composición equilibrada". Por tal ha de entenderse "la presencia de mujeres y hombres de forma que, en el conjunto a que se refiera (una lista de candidaturas), las personas de cada sexo no superen el sesenta por ciento ni sean menos del cuarenta por ciento". La Disposición Adicional Segunda de dicha Ley Orgánica modifica los artículos de la Ley Orgánica de Régimen Electoral relativos a la presentación de candidatos, introduciendo un nuevo art. 44 bis, en virtud del cual las candidaturas que se presenten en la mayoría de los procesos electorales deberán tener una composición equilibrada de mujeres y hombres, respetando la proporción mencionada, esto es, "que en el conjunto de la lista los candidatos de cada uno de los sexos supongan como mínimo el cuarenta por ciento". Las Comunidades Autónomas han tenido que adecuar también sus normas electorales al mandato contenido en esta Ley. Ahora bien, existe la posibilidad de que las Comunidades Autónomas puedan aumentar la proporción indicada a favor de la mujer, aprobando leyes de paridad electoral que introduzcan listas paritarias, como efectivamente ha sucedido en Andalucía, País Vasco, Castilla la Mancha o Baleares. El Tribunal Constitucional se ha pronunciado sobre el art. 44 bis de la LOREG en diferentes ocasiones: SSTC 108 y 127/2007 y 12/2008. Un comentario a esta última sentencia, en la que se había puesto en entredicho la constitucionalidad del precepto citado de la LOREG, puede verse en el trabajo de la profesora BIGLINO CAMPOS, P., "Variaciones sobre las listas de composición equilibrada (Comentario a la STC 12/2008)", Revista Española de Derecho Constitucional, n. ${ }^{\circ}$ 83, 2008, págs. 277-299.

29 Aunque no procede en este momento examinar la naturaleza de esta institución ni la distribución de competencias entre el Estado y la Comunidad Autónoma, sí conviene citar la reciente STC 103/2008, de 11 de septiembre de 2008, en la que se declara la inconstitucionalidad de la Ley del Parlamento Vasco 9/2008, de 27 de junio, "de convocatoria y regulación de una consulta popular al objeto de recabar la opinión ciudadana en la Comunidad Autónoma del País Vasco sobre la apertura de un proceso de negociación para alcanzar la paz y la normalización política». El Tribunal Constitucional analiza lo que debe entenderse por referéndum, desde una perspectiva constitucional, para abordar seguidamente si lo que la Ley impugnada califica como consulta, basada en una pretendida competencia implícita de la Comunidad Autónoma del País Vasco, constituye o no un auténtico referéndum (FFJ 2. ${ }^{\circ}$ y $3 .^{\circ}$ ). El Tribunal considerará que la consulta objeto de la Ley impugnada es constitucionalmente un referéndum y que no existe en nuestro ordenamiento constitucional, en materia de referéndum, ninguna competencia implícita, ya que «en un sistema, como el español, cuya regla general es la democracia representativa, sólo pueden convocarse y celebrarse los referendos que expresamente estén previstos en las normas del Estado, incluidos los Estatutos de Autonomía, de conformidad con la Constitución". De ahí que, por razones competenciales, la Ley recurrida vulnere el art. 149.1.32 CE, en el que se esta- 
Los derechos administrativos, regulados en el art. 12 bajo la denominación del derecho a una "buena Administración", otorgan a los ciudadanos de Castilla y León diversas facultades en sus relaciones con la Administración autonómica, algunas de las cuales ya se hallaban previstas en la legislación estatal o autonómica. Este es el caso del derecho a recibir información suficiente sobre los servicios y prestaciones; el derecho a la resolución de los asuntos en un plazo razonable; el derecho de acceso a los archivos, registros y documentos administrativos; el derecho a la protección de los datos personales; el derecho de acceso en condiciones de igualdad a los empleos públicos en la Administración autonómica; o el derecho a formular quejas sobre el funcionamiento de los servicios públicos ${ }^{30}$. Una de las novedades del art. 12 del Estatuto de Autonomía es la previsión, en su apartado d), de crear una Agencia de Protección de Datos de la Comunidad de Castilla y León, que tendrá por objeto la tutela del derecho a la protección de los datos personales. No obstante, para la creación de esta institución el Estatuto se remite al legislador que habrá de elaborar la correspondiente ley autonómica.

A los derechos sociales se refiere el art. 13 del Estatuto de Autonomía. Sus diversos apartados pueden agruparse en dos tipos de normas. Por un lado, están aquellas disposiciones que enumeran algunos de los derechos sociales clásicos como el derecho a la educación, el derecho la salud, el derecho de acceso a los servicios sociales, los derechos laborales o el derecho a la cultura. Junto a estos derechos, se introduce como novedad el derecho a una renta garantizada de ciudadanía. Por otro lado, se encuentran también aquellas normas que enuncian derechos a favor de determinados grupos de personas que se encuentran en situación de vulnerabilidad o desprotección, como sucede con las personas mayores, los menores, las personas dependientes y los discapacitados. Se trata de normas que conectan directamente con la cláusula social de nuestra forma de Estado.

Aunque no puede acometerse aquí un examen detallado del contenido de estos derechos, sí podemos hacer algunas observaciones. Por ejemplo, se menciona entre los derechos sociales el derecho a la educación, que es una reiteración de lo previsto en el art. 27 de la Constitución, norma que, por otro lado, se halla contenida en el capítulo relativo a los derechos fundamentales. Otra observación que puede hacerse es que no siempre existe una correspondencia clara entre los derechos reconocidos en el Título I y las competencias enumeradas en el Título V del Estatuto. Así ocurre, por ejemplo,

blece la competencia exclusiva del Estado sobre la autorización de convocatoria de consultas populares por vía de referéndum (FJ $\left.3 .^{\circ}\right)$.

30 Una vez más, se elevan a rango estatutario derechos que ya se hallaban regulados en leyes autonómicas o estatales anteriores, como la Ley 7/2005, de 24 de mayo, de la Función Pública de Castilla y León; la LO 15/1999, de 13 de diciembre, de Protección de Datos de Carácter Personal; o la Ley 30/1992, de 26 de noviembre, de Régimen Jurídico de las Administraciones Públicas y Procedimiento Administrativo Común. Con carácter general, puede recordarse también que el art. 41 de la Carta de los Derechos Fundamentales de la Unión Europea alude al derecho a una buena Administración. 
con el derecho a la educación o el derecho de protección a la salud. En este último caso, el art. 13.2 del Estatuto de Autonomía reconoce un conjunto de derechos y deberes a los usuarios del sistema sanitario que excede de las competencias que en el art. 74 del Estatuto se atribuyen a la Comunidad Autónoma. Finalmente, puede considerarse también que las normas estatutarias que atribuyen derechos a determinados colectivos sociales desfavorecidos para hacer efectivo el principio de igualdad, no son verdaderas normas reconocedoras de derechos, sino más bien normas reconocedoras de principios, que deberían de haberse ubicado en el capítulo cuarto, al contener éste mandatos dirigidos a los poderes públicos de la Comunidad Autónoma para lograr la igualdad real y efectiva de todos los ciudadanos.

El capítulo segundo del Estatuto concluye con un precepto, el art. 14, en el que se alude expresamente al principio de igualdad, aunque, como ya se ha adelantado, con un contenido más amplio que el previsto en el art. $14 \mathrm{CE}$, ya que, por un lado, prohíbe todo tipo de discriminación de género, ya sea directa o indirecta ${ }^{31} \mathrm{y}$, por otro, de conformidad con lo dispuesto de forma genérica en el art. 9.2 CE, encomienda a los poderes públicos de Castilla y León la función de garantizar "la transversalidad del principio de igualdad de género en todas sus políticas, promoviendo acciones positivas para lograr la igualdad de oportunidades entre mujeres y hombres" ${ }^{32}$.

c) Los principios rectores de las políticas públicas de Castilla y León se regulan en el capítulo cuarto, que contiene un único precepto de naturaleza heterogénea, el art. 16. En esta disposición se enumeran ampliamente los objetivos (hasta veinticinco) que tratarán de alcanzar los poderes públicos de Castilla y León, dentro del ámbito de sus competencias. Estamos pues ante normas que recogen fines de carácter político, esto es, ante normas que expresan las principales preocupaciones de los ciudadanos, debiendo los poderes públicos autonómicos adoptar aquellas medidas que tiendan a su consecución.

Ahora bien, no todas las normas contenidas en el capítulo cuarto, en el art. 16, tienen una naturaleza similar. Así, existen normas que reiteran -completándolos- algunos de los principios rectores de la política social y económica previstos en la Constitución, como sucede con la protección integral de las distintas modalidades de familia (apartado $13 .^{\circ}$ ) o con la protección de los

31 La ampliación del significado del principio de igualdad en este precepto del reformado Estatuto de Autonomía de Castilla y León, se debe, según expresa la profesora BIGLINO CAMPOS, P., "Derechos y principios...", ob. cit., pág. 149, a la influencia ejercida por normas del Derecho de la Unión Europea, como las Directivas 2002/73 CE y 2004/113 CE. Directivas comunitarias que también introducen la distinción y definición de la discriminación directa e indirecta, que será reproducida en términos semejantes por el art. 6 de la Ley Orgánica 3/2007, de 22 de marzo, para la igualdad efectiva de mujeres y hombres.

32 Además, el apartado segundo del art. 14 del Estatuto establece que la promoción de las acciones positivas por los poderes públicos autonómicos ha de llevarse a cabo especialmente en determinados ámbitos como el «educativo, económico, laboral, en la vida pública, en el medio rural, en relación con la salud y con los colectivos de mujeres en situación de necesidad especial, particularmente las víctimas de violencia de género" 
consumidores y usuarios (apartado $16 .^{\circ}$ ); principios que pueden convertirse en derechos subjetivos cuando sean desarrollados por el legislador. Otras normas del art. 16 guardan, sin embargo, cierta similitud con algunos de los derechos regulados en el capítulo segundo del Título I, como sucede con la promoción de un sistema educativo de calidad (apartado 19. ${ }^{\circ}$ ), en relación con el derecho a una educación pública de calidad (art. 13.1), o con la protección de la salud (apartado 16. ${ }^{\circ}$ ), en relación con el derecho a la protección integral de la salud (art. 13.2). Finalmente, existen otras normas que contienen también obligaciones para los poderes públicos que, sin embargo, no pueden considerarse principios ni normas reconocedoras de derechos subjetivos. Así sucede, por ejemplo, con las que se refieren a la lucha contra la despoblación (apartado 9. ${ }^{\circ}$ ), o a la promoción de la cultura de la paz (apartado $25 .^{\circ}$ ).

Como se ha tenido ocasión de comprobar, la mayoría de los derechos y principios que se contienen en el Título I del Estatuto de Castilla y León, se hallan ya reconocidos en la Constitución española, de ahí que su reiteración por el Estatuto apenas otorgue un plus de protección a los ciudadanos castellanos y leoneses. Con el riesgo añadido de que algunas de las normas estatutarias reconocedoras de ciertos derechos puedan ser decepcionantes para los ciudadanos, al crear en éstos unas expectativas que pueden no ser satisfechas por los poderes públicos ${ }^{33}$.

d) Las garantías de los derechos y principios estatutarios se establecen en el capítulo quinto, que distingue entre unas garantías normativas y judiciales (art. 17) y una garantía institucional, el Procurador del Común (art 18).

La garantía normativa viene determinada por la reserva de ley autonómica prevista en el art. 17.2, al exigir que, en el ámbito autonómico, la regulación esencial de los derechos reconocidos en el capítulo segundo ha de realizarse por ley de las Cortes de Castilla y León.

La garantía jurisdiccional, prevista en el art. 17.1, conlleva que los derechos reconocidos en el capítulo segundo son exigibles en sede judicial bajo las condiciones legalmente establecidas. Garantía judicial que, por otra parte, es inherente a la propia naturaleza de los derechos: éstos o son tutelables ante los órganos judiciales o no son derechos. Por el contrario, los principios rectores de las políticas públicas enumerados en el capítulo cuarto, sólo pueden exigirse judicialmente de acuerdo con lo que establezcan las normas que los desarrollen (art. 17.3).

La garantía institucional del Procurador del Común se regula en el art. 18, teniendo en cuenta seguramente la experiencia acumulada por este órgano estatutario en los años que lleva ejerciendo sus funciones. Así, se le concibe como "el Alto Comisionado de las Cortes de Castilla y León" que, designado por éstas, habrá de actuar con independencia para proteger y defender "los derechos constitucionales de los ciudadanos y los derechos y principios reconocidos en el presente Estatuto frente a la Administración de la Comuni-

33 Como así lo entiende BIGLINO CAMPOS, P., "Derechos y principios...", ob. cit., pág. 155. 
dad, la de sus entes locales y la de los diferentes organismos que de éstas dependan ${ }^{34}$.

\section{LAS COMPETENCIAS DE LA COMUNIDAD: LAS AGUAS Y LA CUENCA DEL DUERO}

El sistema constitucional de distribución de competencias está compuesto por un conjunto de normas y principios que articulan una multiplicidad de materias, secciones de materias y títulos competenciales de difícil ordenación, los cuales se contienen en numerosas disposiciones de la Constitución y de los diecisiete Estatutos de Autonomía ${ }^{35}$.

Como es sabido, este sistema de distribución de competencias entre el Estado y las Comunidades Autónomas viene diseñado por la Constitución que establece un listado de competencias del Estado (art. 149.1) y otro de las Comunidades Autónomas (art. 148), siempre que, en este último caso, las competencias hayan sido asumidas por las Comunidades Autónomas libre y voluntariamente en sus Estatutos (en virtud del principio dispositivo), y con el límite de lo dispuesto en el art. 149.1 CE. El sistema se completa con la cláusula residual de cierre del art. 149.3 CE, que atribuye las competencias no enumeradas en uno u otro listado al Estado.

El Estatuto de Autonomía, como Norma institucional básica de la Comunidad Autónoma, no sólo regula el funcionamiento de los órganos de autogobierno, sino que profundiza en este autogobierno mediante la delimitación de sus competencias, de acuerdo con lo previsto en la Constitución. Antes de la reforma de 2007, el Estatuto de Autonomía de Castilla y León regulaba en su Título II las competencias de la Comunidad estableciendo la siguiente clasificación o tipos de competencias: competencias exclusivas (art. 32); competencias de desarrollo normativo y de ejecución o competencias compartidas (art. 34) y competencias de ejecución (art. 36). Al margen de este tipo de competencias, el Estatuto mencionaba también unas competencias específicas atendiendo a la importancia que las materias tenían para la Comunidad: policía y seguridad pública (art. 33) y educación (art. 35). El sistema competen-

34 Sobre la organización, funcionamiento y competencias de este órgano, así como sus relaciones con el Defensor del Pueblo, vid. la obra colectiva sobre El Procurador del Común. Defensor del Pueblo y Comunidades Autónomas, Valladolid, 1995, págs. 37-144 y CORCHETE MARTÍN, M.J., "El Procurador del Común", en Derecho Público de Castilla y León, Valladolid, 2008, págs. 605-621.

35 Cfr. GARCÍA ROCA, J, "Tipos de normas de deslinde y criterios...”, ob. cit., pág. 708. Para este autor, más que ante un verdadero "sistema" constitucional de distribución de competencias, se está ante un "verdadero rompecabezas", ya que la distribución de competencias no responde a un conjunto de normas ordenado de forma lógica y coherente. Tras las últimas reformas de los Estatutos de Autonomía y el aumento de los preceptos estatutarios destinados a la distribución de competencias, son numerosos los títulos competenciales existentes, pudiendo percibirse de nuevo que no todas las Comunidades Autónomas van a tener las mismas competencias ni el mismo alcance y contenido. 
cial autonómico se cerraba con un precepto que posibilitaba la asunción de nuevas competencias, dentro del marco establecido en art. 148.2 CE, siempre que no se tratase de materias que fuesen competencia exclusiva del Estado y que se aprobara por mayoría absoluta de las Cortes de Castilla y León. De igual modo, se recordaba que la Comunidad Autónoma podía asumir competencias a través de los procedimientos establecidos en el art. 150.1 y 2 CE, así como las demás competencias, funciones y servicios que la legislación del Estado reservara o atribuyese a las Comunidades Autónomas (art. 37).

Con la reforma de 2007, el Estatuto reproduce, en su Título V, el esquema competencial anterior con algunas modificaciones leves. En este sentido, se distinguen también los siguientes tipos de competencias: competencias exclusivas que se ven incrementadas sensiblemente (art. 70); competencias de desarrollo normativo y de ejecución o competencias compartidas, que aumentan considerablemente (art. 71) y competencias de ejecución (art. 76). Se incorporan también en el Estatuto nuevas competencias específicas por la trascendencia de las materias: seguridad pública y policía de Castilla y León (art. 72), educación (art. 73), sanidad (art. 74) y cuenca del Duero y aguas de la Comunidad (art. 75). Se mantiene igualmente un precepto que posibilita a la Comunidad Autónoma asumir competencias a través de los procedimientos del art. 150.1 y $2 \mathrm{CE}$, así como aquellas otras competencias, funciones y servicios que la legislación del Estado reserve o atribuya a las Comunidades Autónomas. No obstante, se introduce como novedad un mandato dirigido a las Cortes y a la Junta de Castilla y León para que velen por que el nivel de autogobierno sea actualizado en términos de igualdad respecto de las demás Comunidades Autónomas (art. 77).

Aunque el Título V aborda, como dice literalmente su rúbrica, las "competencias de la Comunidad", hay que afirmar que este Título, dentro de la clasificación de competencias que establece en sus capítulos, no agota todas las competencias asumidas por la Comunidad de Castilla y León. De esta manera, a lo largo del articulado del Estatuto de Autonomía pueden encontrarse algunos preceptos que, en unos casos, atribuyen nuevas competencias a la Comunidad sobre determinadas materias o que, en otros, concretan y desarrollan materias ya previstas en el Título V. En relación con el primer supuesto, pueden citarse, por ejemplo, los diversos preceptos contenidos en el Título IV, relativo a las relaciones institucionales y acción exterior de la Comunidad de Castilla y León (arts. 60, 62 y 67); o las competencias de la Comunidad en materia de Administración de Justicia (art. 38), ubicadas de forma inadecuada en el capítulo quinto del Título II, dedicado al Poder judicial en Castilla y León. En relación con el segundo supuesto, pueden citarse, por ejemplo, el desarrollo que se hace en el art. 32, relativo a la Administración Autonómica, de la competencia exclusiva que el art. 70.2 atribuye a la Comunidad en materia de estructura y organización de la Administración de la Comunidad; o el desarrollo que se hace en el art. 86, relativo a la organización y competencias de la Hacienda de la Comunidad, de la competencia exclusiva que el art. 70.3 atribuye a la Comunidad en materia de ordenación de la Hacienda de la Comuni- 
dad Autónoma; o el desarrollo que se hace en el art. 46, relativo a la comarca, de la competencia exclusiva que el art. 70.4 atribuye a la Comunidad en materia de organización territorial de la Comunidad.

De todos modos, la ampliación de competencias y la descripción de las materias o secciones de materias competenciales, así como de las funciones o potestades correspondientes a los distintos tipos de competencias que se lleva a cabo con la reforma del Estatuto castellano leonés en 2007, no llega a los niveles de ampliación ni al tratamiento exhaustivo y pormenorizado que de las materias, secciones de materias competenciales y de las funciones propias de los distintos tipos de competencias se hace en los Estatutos de Autonomía de Cataluña y Andalucía ${ }^{36}$.

a) Por lo que se refiere a las competencias exclusivas, el art. 70 las define mediante la atribución de las potestades o funciones que posee la Comunidad sobre una materia, comprendiendo las potestades legislativa y reglamentaria, así como la función ejecutiva, incluida la inspección (apartado segundo). Ahora bien, existen casos en que esa exclusividad no es tal, no es excluyente, pudiendo ser compartida la competencia o sus potestades entre distintos entes. En este sentido, el apartado tercero del art. 70 ya prevé que "la atribución en exclusividad de estas competencias a la Comunidad de Castilla y León se entenderá efectuada sin perjuicio de las competencias que pudieran corresponder al Estado en virtud de otros títulos previstos por la Constitución". Así, puede suceder que sobre una misma materia concurran diferentes títulos competenciales, previéndose incluso expresamente en el Estatuto esta posibilidad mediante la utilización de fórmulas como "sin perjuicio", "en el marco de" o "conforme a". Por ejemplo, el art. 70.1.20. ${ }^{\circ}$ establece que la Comunidad de Castilla y León asume competencia exclusiva en la materia de "comercio interior", añadiendo seguidamente, "sin perjuicio de la política general de precios, de la libre circulación de bienes en el territorio del Estado y de la legislación sobre defensa de la competencia. Regulación y autorización de grandes superficies

36 Vid., sobre estos aspectos, para el Estatuto de Autonomía de Cataluña, VIVER i PI-SUNYER, J., BALAGUER CALLEJÓN, F. y TAJADURA TEJADA, J., La reforma de los Estatutos de Autonomía. Con especial referencia al caso de Cataluña, Madrid, 2005, págs. 16-30, 45-50 y 62-65; SOLOZÁBAL ECHEVARRÍA, J.J., "Sobre las reformas estatutarias y la propuesta del Parlamento catalán", en La reforma de los Estatutos de Autonomía. Actas del VI Congreso Nacional de la Asociación de Constitucionalistas de España (coord. de G. Ruiz-Rico Ruiz), Valencia, 2006, págs. 17-43; CARRILLO LÓPEZ, M., "La delimitación de competencias, entre la Constitución y la Jurisprudencia del Tribunal Constitucional. ¿Qué puede hacer el Estatuto?, en La reforma de los Estatutos de Autonomía. Actas del VI Congreso Nacional de la Asociación de Constitucionalistas de España (coord. de G. Ruiz-Rico Ruiz), Valencia, 2006, págs. 431-435 y VIVER i PI-SUNYER, J., "En defensa de los Estatutos de Autonomía como normas jurídicas delimitadoras de competencias. Contribución a una polémica jurídico constitucional", en el Estado Autonómico, Madrid, 2006, págs, 87-119 y en La reforma de los Estatutos de Autonomía. Actas del VI Congreso Nacional de la Asociación de Constitucionalistas de España (coord. de G. Ruiz-Rico Ruiz), Valencia, 2006, págs. 45-75. Para el Estatuto de Autonomía de Andalucía, puede consultarse el trabajo de IZQUIERDO CARRASCO, M., "Marco general de las competencias de la Comunidad Autónoma de Andalucía en el nuevo Estatuto de Autonomía", El Estatuto de Autonomía de Andalucía de 2007 (coord. de M. Agudo Zamora), Sevilla, 2008, págs. 202-203. 
comerciales, en el marco de la unidad de mercado. Calendarios y horarios comerciales, en el marco de la normativa estatal. Ferias y mercados interiores. Establecimiento de bolsas de valores y establecimiento y regulación de centros de contratación de mercancías, conforme a la legislación mercantil»"37.

Con la reforma se pasa de treinta y cuatro a treinta y siete competencias exclusivas, llevándose a cabo una ordenación, reorganización, actualización o mejora técnica de la definición de los títulos competenciales. Entre las materias o secciones de materias que se introducen dentro de las nuevas competencias exclusivas, pueden destacarse las siguientes: la conservación del Derecho Consuetudinario de Castilla y León; la atención a las mujeres víctimas de violencia de género, dentro de la promoción de la igualdad de trato y de oportunidades entre mujeres y hombres; la acogida e integración económica, social y cultural de los inmigrantes; el desarrollo rural; las denominaciones de origen y organización de los Consejos Reguladores; la investigación científica y técnica, introduciéndose también la sección de materia relativa al fomento y desarrollo de la investigación, al desarrollo e innovación; la cultura, con especial atención a las actividades artísticas y culturales de la Comunidad, comprendiendo algunas secciones de materias ya previstas antes como el patrimonio histórico, los museos o las bibliotecas, e introduciendo otras secciones de materias nuevas como el fomento y la promoción de las producciones artísticas y literarias de Castilla y León o la producción y distribución de libros y publicaciones periódicas en cualquier soporte o la industria cinematográfica y audiovisual de Castilla y León.

b) Por lo que concierne a las competencias de desarrollo normativo y de ejecución o competencias compartidas, éstas se definen en el art. 71 del Estatuto mediante la atribución a la Comunidad de Castilla y León de las facultades de desarrollo legislativo y ejecución de la legislación básica del Estado, en los términos que en ella se establezca (apartado primero). El Estatuto concreta, además, que dichas facultades comprenden la potestad reglamentaria, la gestión y la función ejecutiva, incluida la inspección, sobre una determinada materia (apartado segundo).

Las normas básicas estatales y las competencias autonómicas de desarrollo normativo y de ejecución, como ha dicho el profesor García Roca, son el eje del modelo de distribución de competencias, ya que suponen "una colaboración normativa fundamentada en la segregación entre un marco global que regula el Estado y es, por ello, básico, y una legislación autonómica de desarrollo o complementaria que permite definir el interés de cada Comunidad ${ }^{38}$.

37 El subrayado es nuestro. De ahí que, como ha reiterado el Tribunal Constitucional en ciertas ocasiones, algunas competencias exclusivas no son tales, dado "el sentido marcadamente equívoco con el que el adjetivo exclusivo se utiliza tanto en el texto de la Constitución como en el de los Estatutos de Autonomía". Cfr. las SSTC 37/1981, de 16 de noviembre (FJ 1. ${ }^{\circ}$ ) y 5/1982, de 8 de febrero (FJ $1 .^{\circ}$ ).

38 Cfr. GARCÍA ROCA, J., "Tipos de normas de deslinde y criterios...", ob. cit., pág. 725 , quien se plantea algunas cuestiones acerca de qué es lo básico, cómo se define, qué ocurre en 
Con la reforma se pasa de doce a diecisiete competencias compartidas, llevándose a cabo también una ordenación, actualización y mejora técnica de la definición de los títulos competenciales. Entre las materias o secciones de materias que se introducen dentro de las nuevas competencias compartidas, pueden destacarse las siguientes: la protección de datos de carácter personal que estén bajo la responsabilidad de las instituciones de la Comunidad; la seguridad social, con la excepción de alguna sección de materia como es el régimen económico (materia que con anterioridad a la reforma estatutaria era competencia de ejecución); las tecnologías de la información y el conocimiento; la protección civil, incluyendo expresamente algunas funciones como la regulación, planificación y ejecución de medidas relativas a las emergencias y la seguridad civil, así como la coordinación y formación de los servicios de protección civil, entre ellos los de prevención y extinción de incendios; las asociaciones que desarrollen principalmente sus actividades en la Comunidad Autónoma (materia que con anterioridad a la reforma era también competencia de ejecución).

En algunos casos, la legislación estatal puede vincular la legislación autonómica complementaria o de desarrollo de una materia de competencia compartida. La vinculación de la ley autonómica a la ley estatal puede proceder de la Constitución o del Estatuto y se realiza mediante fórmulas como «en el marco" o "en los términos" que la ley establezca. Por ejemplo, el art. 72 del Estatuto atribuye competencias en materia de seguridad pública a la Comunidad Autónoma de Castilla y León, en concreto la vigilancia y protección de sus edificios e instalaciones, pudiendo convenir, para ello, con el Estado la adscripción de una Unidad del Cuerpo Nacional de Policía, en los términos y para el ejercicio de las funciones previstas en la Ley Orgánica a que se refiere el número 29 del artículo 149.1 de la Constitución (LO 2/1986, de 13 de marzo de Fuerzas y Cuerpos de Seguridad del Estado). Asimismo, como novedad, la Comunidad de Castilla y León podrá crear, mediante ley de Cortes, un Cuerpo de Policía de Castilla y León, que ejercerá las funciones que dicha ley establezca y aquellas otras en colaboración con las Fuerzas y Cuerpos de Seguridad del Estado previstas en la Ley Orgánica reguladora de éstos.

c) Las competencias de ejecución, que podrían concebirse también como un supuesto de competencias compartidas, se definen en el art. 76 del Estatuto mediante la atribución a la Comunidad de Castilla y León de la función ejecutiva sobre una determinada materia, en los términos que establezcan las leyes y las normas reglamentarias que en su desarrollo dicte el Estado. La esencia de este tipo de competencias reside en la colaboración existente entre un ente que aprueba la legislación para todo el Estado y otro que la ejecuta con cierta libertad para adecuarla al pluralismo territorial ${ }^{39}$.

el caso de que surja un conflicto entre las bases y las normas de desarrollo. Para dar respuesta a estas cuestiones, el autor acude a la jurisprudencia del Tribunal Constitucional.

39 Vid. GARCÍA ROCA, J., "Tipos de normas de deslinde y criterios...", ob. cit., pág. 733. La función ejecutiva comprenderá un amplio abanico de actividades como la elaboración de reglamentos organizativos, resoluciones y actos administrativos, facultades de inspección y sanción... 
Con la reforma se mantiene el número de quince apartados en los que se enumeran las materias objeto de competencias ejecutivas, aunque algunas, según se ha dicho antes, han pasado a ser competencias compartidas o de desarrollo normativo o de ejecución, como la seguridad social o las asociaciones. También se introducen nuevas materias de competencia ejecutiva como el empleo y las relaciones laborales; las políticas activas de ocupación; la prevención de riesgos laborales; la promoción de la salud y seguridad laboral; la seguridad privada, cuando así lo establezca la legislación del Estado; Notarios y Registradores de la Propiedad, Mercantiles y de Bienes Muebles; o la defensa de la competencia.

El Título V del Estatuto, dedicado a las competencias de la Comunidad, concluye con un precepto, el art. 77 , en el que se alude a los procedimientos para la asunción de nuevas competencias. En su apartado $3 .^{\circ}$, se establece una cláusula de igualación o nivelación competencial. Contiene una norma eminentemente de carácter finalista, al encomendar a las Cortes y a la Junta de Castilla y León la obligación de velar para que el nivel de autogobierno "sea actualizado en términos de igualdad respecto de las demás Comunidades Autónomas".

Se trata de una norma inspirada en la que se ha conocido coloquialmente como "cláusula Camps", contenida en la Disposición Adicional Primera del Estatuto de la Comunidad Valenciana, pero redactada con una técnica más correcta o con mayor rigor jurídico. La norma del Estatuto valenciano pretende que cualquier modificación de la legislación del Estado que implique una ampliación de las competencias de las Comunidades Autónomas sea "de aplicación a la Comunidad Valenciana, considerándose ampliadas en esos mismos términos sus competencias". Estamos, pues, ante una norma inútil, ante una norma de difícil o imposible cumplimiento, porque no puede existir un procedimiento automático de nivelación competencial, esto es, de actualización automática de competencias en un Estatuto en relación con las reformas que se hayan producido en otros Estatutos. Otra cosa hubiese sido que dicha cláusula se interpretara como la previsión en el Estatuto de una especie de recomendación destinada a los órganos competentes para que insten los procedimientos dirigidos a lograr esa igualación competencial.

\section{Las aguas y la cuenca del Duero}

Una de las nuevas competencias específicas que se incorporan al Estatuto es la contenida en el art. 75 , relativa a la cuenca del Duero y a las aguas de la Comunidad.

El agua, en palabras de Garrorena Morales, es una "materia sensible para toda la comunidad", habiéndo llegado a convertirse en "objeto constitucional", ya sea como consecuencia de un "empeño territorial del Estado" (Holanda), ya sea por la "potencial tensión" que puede originar el reparto de competen- 
cias en un Estado descentralizado, que puede derivar en un "calentamiento constitucional del tema" ${ }^{40}$.

Como ha manifestado la profesora Caro-Patón, el agua, quizás, sea una de las competencias "estrella" en el proceso de reforma de los Estatutos de Autonomía, ya que la mayoría de las Comunidades Autónomas han reivindicado su competencia sobre este recurso natural, incluida también la Comunidad de Castilla y León que, en su Estatuto de Autonomía pretende, por un lado, asumir competencias sobre el Duero y, por otro, atribuir a los poderes públicos de la Comunidad la función de garantizar el abastecimiento del agua para atender las necesidades de los castellanos y leoneses ${ }^{41}$.

Conforme a lo dispuesto en el art. 149.1.22 CE, el Estado tiene atribuida una competencia exclusiva sobre la «legislación, ordenación y concesión de los aprovechamientos hidráulicos cuando las aguas discurran por más de una Comunidad Autónoma". La Ley 29/1985, de 2 de agosto, de Aguas, ha habilitado al Estado para asumir todas las funciones de legislación, planificación y ejecución de las cuencas de los ríos que discurran por más de una Comunidad Autónoma (aguas o cuencas intercomunitarias). Ahora bien, de esta afirmación no puede deducirse, como ha reconocido el Tribunal Constitucional en la decisiva STC 227/1988, de 29 de noviembre, que para el resto de las aguas, las que trascurran por una Comunidad Autónoma (aguas intracomunitarias), el Estado no pueda ejercer ningún tipo de competencia, ya que, en relación con este tipo de aguas, pueden actuar otros títulos de intervención que permitan al Estado elaborar una normativa básica ${ }^{42}$.

Por regla general, de la Ley de Aguas y de la interpretación que de ella ha hecho el Tribunal Constitucional en la citada STC 227/1988, la expresión del art. 149.1.22 CE «las aguas que discurran por más de una Comunidad Autónoma", se identifica con las aguas de las cuencas de los ríos que traspasan el territorio de una Comunidad Autónoma. Para el Tribunal Constitucional, no es inconstitucional que la Ley de Aguas utilice como criterio territorial, para el ejercicio de las competencias del Estado en materia de aguas continentales,

$40 \mathrm{Vid}$. GARRORENA MORALES, A., "El derecho del agua ante la reforma de la Constitución y de los Estatutos de Autonomía", Teoría y Realidad Constitucional, n. ${ }^{2}$ 20, 2007, págs. 78-79. "Calentamiento constitucional", que ha dado lugar a un espectáculo poco edificante como consecuencia de los recursos de inconstitucionalidad interpuestos por unas Comunidades Autónomas contra otras, a causa de la regulación que del tema del agua se ha hecho en sus Estatutos (pág. 102). Sobre la gestión del agua en los estados federales es de obligada consulta el libro de EMBID IRUJO, A. (Dir.) y HÖLLING, M. (Coord.), Gestión del Agua y Descentralización Política, Pamplona, Thomson Reuters, Aranzadi, 2009, en el que se recoge una emplia y actualizada información sobre la gestión del agua en los países que han adoptado esa forma de organización territorial del Estado.

41 Cfr. CARO-PATÓn CARMONA, I., "Aguas y cuenca del Duero", en Derecho Público de Castilla y León, Valladolid, 2008, págs. 1068-1069.

42 Puede pensarse, por ejemplo, en lo relativo al régimen jurídico de las concesiones, para las que el art. 149.1.18 CE afirma el carácter básico de las competencias estatales, aunque ello pueda dar lugar también a un planteamiento equívoco, como expresa EMBID IRUJO, A., "Medio ambiente", en El Estatuto de Autonomía de Andalucía de 2007 (coord. de M. Agudo Zamora), Sevilla, 2008, pág. 305. 
el de la cuenca hidrográfica que exceda de una Comunidad Autónoma. Ahora bien, el Tribunal precisa también que este criterio territorial no es el único que deba tenerse en cuenta. En consecuencia, puede ser constitucional también la utilización de otros criterios como el "curso del agua" o la "demarcación hidrográfica" (STC 227/1988, FJ 15.'). De esta manera, sería también conforme a la Constitución la asunción de una competencia exclusiva por el Estado, en los términos del art. 149.1.22 CE, sobre la cuenca de un río, aunque algo menos del $2 \%$ de todas las aguas de su cuenca discurra por varias Comunidades (como sucede, por ejemplo, con la cuenca del río Duero). Dicho de otro modo, el Estado podría asumir la competencia exclusiva sobre la cuenca de un río, aunque el $98 \%$ del total de la cuenca comprenda el territorio de una Comunidad Autónoma (se presumiría, en este caso, que las aguas discurren preferentemente por una Comunidad Autónoma) ${ }^{43}$.

Con la reforma, el Estatuto, a la hora de regular las competencias sobre la cuenca del Duero y las aguas de la Comunidad, tiene en cuenta la naturaleza castellano leonesa de la cuenca del Duero, partiendo de su concreta realidad geográfica, conforme a la cual todos los grandes ríos que integran la cuenca del Duero nacen en Castilla y León y sus aguas pasan a Portugal sin atravesar ninguna otra Comunidad Autónoma ${ }^{44}$. La interpretación que se hace en el Estatuto de Autonomía de Castilla y León del art. 149.1.22 CE, implica

43 Conforme a esta doctrina fijada por el Tribunal Constitucional, para la profesora CAROPATÓN (pág. 1062), al no definir el art. 149.1.22 CE el criterio en virtud del cual el Estado puede asumir competencia exclusiva sobre las aguas de un río, este criterio puede ser determinado por el legislador estatal en una ley sectorial (la Ley de Aguas), pero también en los Estatutos de Autonomía. De este modo, la solución establecida en la Ley de Aguas de 1985 no es la única constitucionalmente posible, sino que en un Estado fuertemente descentralizado, como el español, también caben otras soluciones previstas en los Estatutos de Autonomía, de acuerdo con las competencias autonómicas asumidas.

44 Sobre la peculiaridad geográfica de la cuenca del Duero, verdadero hecho diferencial de Castilla y León, vid. KROTEMBERG VÁZQUEZ, J., "La cuenca del Duero como hecho diferencial de Castilla y León", Revista Juridica de Castilla y León, n. 11, 2007, págs. 173-204.

El dictamen del Consejo Consultivo de Castilla y León 381/2004, de 29 de junio, sobre las posibles vías para asumir competencias y facultades, dentro del marco constitucionalmente previsto, en materia de recursos y aprovechamientos hidráulicos, aludía también al "hecho diferencial" que supone el río Duero como elemento fundamental en la vertebración de Castilla y León: "El río Duero forma parte del paisaje espiritual y físico de Castilla y León (...), de la historia y la cultura de esta tierra. Baste recordar que en sus habitantes ha cuajado un verdadero sentimiento filial hacia él, pues no en vano es llamado el "padre Duero" (...), que tan profundamente conforma la realidad social y económica castellano-leonesa (...). Sin riesgo alguno de exageración, puede afirmarse que ninguna otra Comunidad Autónoma presenta un carácter geográfico tan acusadamente centrado en una cuenca hidrográfica como Castilla y León en relación con la del Duero (...) En España, la cuenca del Duero es Castilla y León y Castilla y León es la cuenca del Duero". La Disposición Adicional Tercera del anterior Estatuto de Autonomía, introducida por la reforma de 1999 (LO 4/1999, de 8 de enero) suponía ya un intento de atribuir a la Comunidad Autónoma la competencia de ejecución en la gestión de las aguas de la cuenca del Duero. Así, por un lado, se reconocía expresamente la importancia que la cuenca del Duero tiene para nuestra Comunidad como elemento configurador de su territorio y, por otro, se posibilitaba la celebración de convenios de cooperación entre el Estado y la Comunidad para la gestión de las aguas de la cuenca del Duero. 
que las competencias exclusivas del Estado sobre la cuenca del Duero recaerían sobre aquellas aguas que discurran efectivamente sobre otras Comunidades Autónomas.

De este modo, se opta por incluir la materia de recursos y aprovechamientos hidráulicos de las aguas de la cuenca del Duero como competencia de desarrollo legislativo y ejecución de la Comunidad Autónoma, dada la importancia que tiene la cuenca del Duero como elemento configurador del territorio de Castilla y León, y siempre que dichas aguas tengan su nacimiento en Castilla y León y deriven a Portugal sin atravesar ninguna otra Comunidad Autónoma (art. 75.1).

Esta nueva redacción, respetuosa con la Norma constitucional, supone, como ha reconocido la profesora Caro-Patón, que el Estado ha admitido el traspaso de las competencias de desarrollo normativo y ejecución que hasta ahora le correspondían y que ejercía a través de la Confederación hidrográfica $^{45}$.

El apartado cuarto del art. 75, que reproduce lo dispuesto en el anterior art. 32.6 del Estatuto, atribuye a la Comunidad la competencia exclusiva en materia de proyectos, construcción y explotación de los aprovechamientos hidráulicos, canales y regadíos de interés de la Comunidad Autónoma; aguas minerales, termales y subterráneas, ordenación y concesión de recursos y aprovechamientos hidráulicos, canales y regadíos, siempre que se trate de aguas que discurran íntegramente dentro del territorio de Castilla y León, es decir, de aguas intracomuniarias.

Por lo que se refiere al resto de las aguas, esto es, las pertenecientes a otras cuencas intercomunitarias que se encuentren en el territorio de Castilla y León, la Junta de Castilla y León podrá participar en su gestión colaborando con el Estado y las demás Comunidades Autónomas (art. 75.2). Todo ello sin perjuicio de la competencia exclusiva que tiene el Estado en materia de planificación hidrológica (art. 75.3). El Estado, conforme a lo dispuesto en el art. 1.4 de la Ley de Aguas, tiene la competencia para aprobar un plan hidrológico nacional y planes de cuenca, con independencia de que se trate de aguas intracomunitarias o intercomunitarias.

45 Cfr. CARO-PATÓN CARMONA, I., "Aguas y cuenca del Duero...", ob. cit., págs. 1063-1064, apoyándose en un dictamen emitido por el profesor MARTÍNEZ LÓPEZ-MUÑIZ. Castilla y León representa el 98,31\% del total de la superficie española de la cuenca, mientras que el 1,69 \% representa a las Comunidades Autónomas de Galicia, Cantabria, La Rioja, Castilla-La Mancha, Extremadura y Madrid (dictamen del Consejo Consultivo de Castilla y León 381/2004, de 29 de junio). Para la profesora Caro-Patón, aunque el traspaso de competencias no requiere la reforma de la Ley de Aguas; por el contrario, sí sería necesario acometer una modificación en profundidad de todos o algunos de los organismos de cuenca, ya que actualmente no están adaptados a las exigencias de la gestión de los recursos hídricos (págs. 1080-1081). A diferencia del Estatuto de Autonomía de Castilla y León, el Estatuto de Autonomía de Andalucía, en su art. 51, atribuye a la Comunidad Autónoma competencias exclusivas sobre las aguas de la cuenca del Guadalquivir que transcurren por su territorio y no afecten a otra Comunidad Autónoma. Acerca de las posibles interpretaciones de este precepto, y estando a la espera de lo que diga en su día el Tribunal Constitucional, vid., EMBID IRUJO, A., "Medio ambiente...", ob. cit., págs. 308-309. 
El apartado quinto del art. 75 reconoce a favor de los castellanos y leoneses una garantía de abastecimiento de agua en condiciones de cantidad y calidad suficientes para atender las necesidades presentes y futuras. Lo concibe también como un principio rector de la acción política de la Comunidad, lo que conlleva unas obligaciones para los poderes públicos autonómicos, mencionando expresamente la necesidad de emitir un informe preceptivo (aunque no vinculante) por parte de la Junta de Castilla y León sobre cualquier decisión estatal que implique transferencia de aguas fuera del territorio de la Comunidad, y ello dentro del marco de la legislación del Estado. Esta garantía, este principio rector se corresponde con la atribución en otros Estatutos a los ciudadanos de la Comunidad Autónoma de un derecho al aprovechamiento de las aguas que discurran por su territorio o, si tuviesen cuencas deficitarias, al aprovechamiento de las aguas sobrantes de otros territorios ${ }^{46}$.

\section{LA REFORMA DEL ESTATUTO}

La Constitución, como es bien sabido, hace referencia a la reforma de los Estatutos de Autonomía en dos preceptos: los arts. 147.3 y $152.2 \mathrm{CE}^{47}$. La primera norma, el art. 147.3 CE, exige que la reforma de los Estatutos de Autonomía haya de aprobarse en las Cortes Generales "mediante ley orgánica". Se trata de un requisito procedimental de carácter general, aplicable a los Estatutos de todas las Comunidades Autónomas y que ha de ponerse en relación con el art. 81.1 CE. La segunda norma, el art. 152.2 CE, exige que la modificación de los Estatutos de Autonomía haya de aprobarse "con referéndum entre los electores inscritos en los censos correspondientes". Se trata de un requisito procedimental de carácter específico o complementario, aplicable a los Estatutos de las Comunidades Autónomas que accedieron a la autonomía por la vía rápida del art. $151.1 \mathrm{CE}^{48}$.

46 Este es el caso de la Disposición Adicional Quinta del Estatuto de Aragón, en la que se proclama el principio de prioridad para el aprovechamiento del Ebro, en los términos en los que lo concrete la planificación hidrológica y considerando las inversiones comprendidas en el Pacto del agua de Aragón y la prohibición de realizar trasvases que afecten a los intereses de la sostenibilidad de la cuenca (art. 19). Este sería el caso también del art. 17.1 del Estatuto de Autonomía de la Comunidad de Valencia (con la reforma de la LO 1/2006, de 10 de abril), en el que se reconoce a los valencianos el derecho de redistribución de los sobrantes de aguas de cuencas excedentarias, declarado constitucional por la STC 247/2007, de 12 de diciembre, como se ha visto supra, en el epígrafe III de este trabajo.

47 REVENGA SÁNCHEZ, M., "El procedimiento de reforma", en El Estatuto de Autonomía de Andalucía de 2007 (coord. de M. Agudo Zamora), Sevilla, 2008, pág. 361, pone de manifiesto cómo el hecho de que la Constitución se ocupe de regular ciertos aspectos de la reforma de los Estatutos de Autonomía "ya es algo que nos pone sobre la pista de la importante función constitucional de los mismos".

48 Sobre estos requisitos o exigencias procedimentales, vid. ARAGÓN REYES, M., "La reforma de los Estatutos de Autonomía...", ob. cit., págs. 385-386. Además de las dos normas constitucionales citadas, habría que mencionar también otro precepto, el art. 148.2 CE, en el que la reforma del Estatuto surge con la posibilidad de llevar a cabo una ampliación competencial, una 
La reforma de los Estatutos de Autonomía no sólo tiene por función adecuar la norma a la realidad cambiante, sino también garantizar al propio Estatuto frente a las normas estatales y autonómicas que pretendieran eventualmente modificarla. De ahí que la rigidez estatutaria pueda considerarse también como una garantía permanente de la autonomía y de la estabilidad del sistema de descentralización territorial ${ }^{49}$.

El Estatuto de Autonomía de Castilla y León, antes de la reforma, regulaba en su Título IV (art. 55) un procedimiento para su propia reforma ${ }^{50}$, que constaba de las siguientes fases: a) la iniciativa de reforma que correspondía a las Cortes de Castilla y León, a propuesta de una tercera parte de sus miembros, a la Junta de Castilla y León y a las Cortes Generales; b) la propuesta de reforma requería, en todo caso, la aprobación de las Cortes de Castilla y León por mayoría de dos tercios y la posterior aprobación de las Cortes Generales mediante ley orgánica; c) en el caso de que la propuesta de reforma no fuese aprobada por las Cortes de Castilla y León o por las Cortes Generales, no podría ser sometida nuevamente a debate y votación de aquéllas hasta que hubiese transcurrido más de un año.

Este procedimiento de reforma, denominado como procedimiento ordinario de reforma, era muy similar al previsto en los Estatutos de las Comunidades Autónomas que accedieron a la autonomía por la vía lenta. Junto a él, existían otros procedimientos especiales de reforma, que atendían a la posible modificación del ámbito territorial de Castilla y León (Disposiciones Transitorias Séptima y Octava) ${ }^{51}$ o a la asunción de nuevas competencias (art. 37.2).

Con la reforma, el Estatuto regula también un procedimiento ordinario de reforma, en el Título VII (art. 91) y algún procedimiento especial de reforma referido, sobre todo, a la alteración del ámbito territorial de la Comunidad.

El procedimiento ordinario de reforma se caracteriza por la intervención de dos órganos legislativos, el estatal y el regional, que dialogan entre

vez que hayan transcurrido cinco años desde que las Comunidades Autónomas del art. 143 CE accedieran a la autonomía. Norma que ya ha sido superada después de haber pasado los cinco años y de que las Comunidades Autónomas citadas hayan experimentado diversas reformas estatutarias para ampliar sus competencias.

49 Vid. REY MARTÍNEZ, F., "Procedimiento de reforma estatuaria", en Derecho Público de Castilla y León, Valladolid, 2008, pág. 182. El profesor CASCAJO CASTRO, J:L., "Sobre la reforma de los Estatutos de Autonomía: anotaciones de un oyente", en La reforma de los Estatutos de Autonomía, Valladolid, 2003, pág. 20, alude también al "valor de garantía" que conlleva "toda operación de reforma de un texto normativo, conforme al procedimiento de cambio previsto por él mismo".

50 Procedimiento que, como se ha indicado al principio de este trabajo, se ha utilizado en tres ocasiones: con las reformas de 1994, mediante la LO 11/1994, de 24 de marzo; de 1999, mediante la LO 4/1999, de 8 de enero y de 2007, mediante la citada LO 14/2007, de 30 de noviembre.

$51 \mathrm{Al}$ comprender algunos supuestos como la posibilidad de que alguna Comunidad Autónoma se incorpore a la nuestra, o la incorporación de una provincia limítrofe al territorio de la Comunidad de Castilla y León; o la segregación de un enclave perteneciente a una provincia integrada en nuestra Comunidad y su incorporación a otra Comunidad. 
$s^{52}$. De ahí que se haya manifestado también que con la reforma se aúnan las voluntades de dos órganos deliberantes y parlamentarios ${ }^{53}$, o que mediante ella se expresa a la vez la voluntad parcial de los ciudadanos de las correspondientes Comunidades Autónomas y la voluntad global del conjunto de los ciudadanos del pueblo español ${ }^{54}$. Las fases del procedimiento ordinario de reforma son las siguientes:

a) La propuesta de iniciativa de la reforma: poseen la potestad de proponer la iniciativa de reforma del Estatuto el órgano de gobierno de la Comunidad, la Junta de Castilla y León y una fracción del órgano legislativo autonómico, una tercera parte de los miembros de las Cortes de Castilla y León (art. 91.1). Se suprime, por tanto, la potestad de proponer la iniciativa de reforma del Estatuto a las Cortes Generales. Sin embargo, a diferencia de otros Estatutos de Autonomía, no se otorga la potestad para proponer la iniciativa de reforma del Estatuto a un determinado número de municipios que representen, al menos, la mayoría del censo electoral ${ }^{55}$.

b) Aprobación de la propuesta de reforma: la propuesta de iniciativa de la reforma requerirá la aprobación de las Cortes de Castilla y León por mayoría de dos tercios y la posterior aprobación de las Cortes Generales mediante ley orgánica (art. 91.2). El texto aprobado por las Cortes de Castilla y León no es una ley autonómica. Se trata más bien de un "texto-iniciativa" del procedimiento legislativo que se desarrollará posteriormente en las Cortes Generales ${ }^{56}$.

Una vez que el texto de iniciativa de reforma del Estatuto ha sido aprobado por las Cortes de Castilla y León, pasa a las Cortes Generales para su aprobación mediante ley orgánica (art. 91.2 del Estatuto, en relación con el art. 147.3 CE). Para cubrir una laguna existente e introducir ciertos límites a la amplia capacidad de enmienda que sobre el texto de iniciativa de reforma tendrían las Cortes Generales, determinadas resoluciones de la Presidencia del Congreso y del Senado permitirán a los parlamentos autonómicos retirar el proyecto de reforma del Estatuto antes de que se apruebe definitivamente por las Cortes Generales ${ }^{57}$.

52 Aunque, como dice REY MARTÍNEZ, F., "Procedimiento de reforma estatuaria...”, ob. cit., pág. 184, se trate de un diálogo desigual porque, desde la lógica del principio de autonomía del art. $2 \mathrm{CE}$, el parlamento regional asumirá, como se verá, un protagonismo mayor en la tramitación parlamentaria.

53 Cfr. GARCÍA ROCA, J., "Tipos de normas de deslinde y criterios...", ob. cit., pág. 717.

$54 \mathrm{Vid}$. REVENGA SÁNCHEZ, M., "El procedimiento de reforma...", ob. cit., pág. 361.

55 Un tercio de los municipios para el caso de Murcia; dos tercios para el caso de Asturias, La Rioja, Madrid y Cataluña.

56 Cfr. AGUADO RENEDO, C., El Estatuto de Autonomía y su posición..., ob. cit., págs. 417419 y REY MARTÍNEZ, F., "Procedimiento de reforma estatutaria...”, ob. cit., págs. 185-186.

57 Se trata de la Resolución de la Presidencia del Congreso de los Diputados, de 16 de marzo de 1993 y de la Norma Supletoria de la Presidencia del Senado, de 30 de septiembre de 1993. 
La reforma introduce dos apartados en el art. 91 (el tercero y el cuarto) que tienden, por un lado, a garantizar la presencia de parlamentarios autonómicos en el Congreso y en el Senado y, por otro, a que sea el parlamento regional el que tenga la última palabra sobre la reforma del Estatuto cuando el texto haya sufrido modificaciones en su tramitación ante las Cortes Generales.

El art. 91.3 establece que, una vez que haya sido «aprobada la propuesta de reforma por las Cortes de Castilla y León, se remitirá al Congreso de los Diputados. Las Cortes de Castilla y León elegirán de entre sus miembros una delegación para participar en la tramitación de la propuesta en el seno de una comisión mixta paritaria constituida de acuerdo con el procedimiento que prevea el Reglamento del Congreso de los Diputados".

El art. 91.4 dispone que «las Cortes de Castilla y León podrán retirar con la mayoría cualificada que determine su Reglamento la propuesta de reforma en cualquier momento de la tramitación en las Cortes Generales antes de que sea aprobada de forma definitiva. En este caso no será de aplicación lo dispuesto en el apartado siguiente, ${ }^{58}$.

En definitiva, con la modificación del procedimiento ordinario de reforma estatutaria, se configura un nuevo cauce de tramitación ante el Parlamento estatal, en el que han de estar representados miembros de las Cortes de Castilla y León y en el que se faculta a éstas para que desistan de la reforma frente a las Cortes Generales. De esta manera, nuestro parlamento autonómico tiene la primera y la última palabra de las próximas reformas estatutarias ${ }^{59}$.

El art. 91.5 prevé un último supuesto para el caso de que la propuesta de reforma no haya sido aprobada por las Cortes de Castilla y León o por las Cortes Generales. Ante este fracasado intento de reforma, no se podrá someter la propuesta de reforma "nuevamente a debate y votación de aquéllas hasta que haya transcurrido al menos un año".

Finalmente, en relación con las fases del procedimiento ordinario de reforma, ha de mencionarse que la reforma de 2007 de nuestro Estatuto de Autonomía, a diferencia de los Estatutos de las Comunidades Autónomas que accedieron a la autonomía por la vía rápida y de algunas que lo hicieron por la vía lenta, no ha introducido como novedad la posibilidad de convocar un referéndum de ratificación de la reforma estatuaria.

Sobre la situación anterior y posterior a estas resoluciones, vid. ARAGÓN REYES, M., "La reforma de los Estatutos de Autonomía...", ob. cit., págs. 397-403.

58 Esta posibilidad se había introducido ya en la Resolución de la Presidencia de las Cortes de Castilla y León de 1 de diciembre de 2006; fecha en la que se estaba tramitando la reforma del Estatuto de Autonomía de Castilla y León.

59 En términos similares se expresa el profesor REY MARTíNEZ, F., "Procedimiento de reforma estatuaria...", ob. cit., pág. 183, cuando reconoce que la preocupación mayor de las instituciones autonómicas ha sido la de ser en todo momento "dueñas" del procedimiento de reforma, desde el momento inicial, a partir de la voluntad de reforma manifestada a través de la iniciativa ejercida invariablemente por ellas, hasta el momento final, con la posibilidad de retirar la proposición de reforma del Estatuto durante su tramitación en las Cortes Generales. 
Por lo que se refiere a los procedimientos especiales de reforma del Estatuto, ha de manifestarse que la reforma deroga el procedimiento especial relativo a la ampliación de determinadas competencias. En lo que concierne al procedimiento especial relativo a la modificación del ámbito territorial de la Comunidad, se suprimen las cautelas que establecía el Estatuto anterior respecto de dos Comunidades Autónomas vecinas, La Rioja y Cantabria, que históricamente han venido manteniendo vínculos con la nuestra. Se ha erradicado también el supuesto previsto en la anterior Disposición Transitoria Séptima, sobre la posible incorporación de la provincia limítrofe de Segovia al territorio de nuestra Comunidad. Sin embargo, sí ha mantenido el procedimiento relativo a la segregación de un municipio o territorio que constituya un enclave de una provincia integrada en nuestra Comunidad y su incorporación a otra. De hecho, añade un requisito más, como es la necesidad de que la solicitud de segregación ha de ser formulada por todos los Ayuntamientos interesados mediante un acuerdo adoptado con el voto favorable de las dos terceras partes del número de hecho y, en todo caso, de la mayoría absoluta de los miembros de cada una de dichas Corporaciones.

TIтL: The Statutarie reform in Castilla y León: the principal changes.

ABSTRACT: The Statute of Autonomy of Castilla y León has been reformed recently, in november of 2007. In this article, the author analyses some of the main changes that have been introduced in the Statute with that reform. Particularly, some of identity signes of Castilla y León, like the definition of our Autonomic Community, territory and language. Also, it has been examined the incorporation, in a new Title, of a Bill of Rights Castilla y Leon cityzens' and the principles rectors publics polities Autonomic Community's. In the other way, it has been analysed the competences system of our the Autonomic Community, specially, the competence about the Duero's river. Finally, the author do some considerations about the reform procedure of the Statute of Autonomy.

RESUMEN: El Estatuto de Autonomía de Castilla y León ha sido reformado en noviembre de 2007. En este articulo, el autor analiza algunas de las novedades principales que se han introducido en el Estatuto con motivo de dicha reforma. En particular, algunas de las señas de identidad de Castilla y León como la definición de la Comunidad Autónoma, el territorio y la lengua. También se examina la incorporación que se ha realizado, en un nuevo Título, de los derechos de los ciudadanos castellanos y leoneses y de los principios rectores de las políticas públicas de la Comunidad. Por otro lado, se ha analizado también el sistema de distribución de competencias de nuestra Comunidad, deteniéndose, particularmente, en la competencia sobre las aguas del Duero. Finalmente, el autor hace algunas consideraciones sobre el procedimiento de reforma del Estatuto de Autonomía. mic State.

KeY wORDs: Statutes of Autonomy, The Statutarie reforms, Competences system in the Autono-

Palabras clave: Estatutos de Autonomía, Reformas de los Estatutos de Autonomía, Sistema de distribución de competencias en la forma de Estado autonómico. 